\title{
RECEIVED
}

OCT 201995

OSTI

\section{Structural Vibration Control of Micro/Macro-Manipulator Using Feedforward and Feedback Appróaches}
J.Y. Lew
D. W. Cannon
D.P.Magee
W.J. Book

September'1995

Prepared for

the U.S. Department of Energy

Contract DE-AC06-76RLO 1830

Pacific Northwest Laboratory

Operated for the U.S. Department of Energy

by Battelle Memorial Institute

$\%$ Battelle

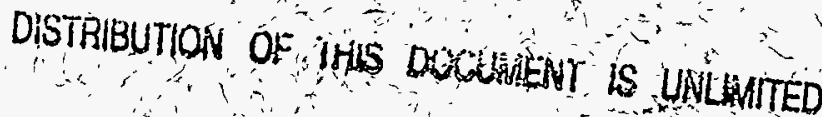




\section{DISCLAIMER}

Portions of this document may be illegible in electronic image products. Images are produced from the best available original document. 


\title{
Structural Vibration Control of Micro/Macro-Manipulator Using Feedforward and Feedback Approaches
}

\author{
J. Y. Lew \\ D. W. Cannon ${ }^{(a)}$ \\ D. P. Magee (b) \\ W. J. Book ${ }^{(b)}$
}

September 1995

Prepared for

the U.S. Department of Energy

Office of Technology Development

under Contract DE-AC06-76RLO 1830

Pacific Northwest Laboratory

Richland, Washington 99352

(a) Associated Western University (AWU) Northwest Division Graduate Fellowship

(b) Georgia Institute of Technology Atlanta, Georgia 


\section{.}

, 


\section{Abstract}

Pacific Northwest Laboratory (PNL) researchers investigated the combined use of two control approaches to minimize micro/macro-manipulator structural vibration: 1) modified input shaping and 2) inertial force active damping control. Modified input shaping (MIS) is used as a feedforward controller to modify reference input by canceling the vibratory motion. Inertial force active damping (IFAD) is applied as a feedback controller to increase the system damping and robustness to unexpected disturbances.

Researchers implemented both control schemes in the PNL micro/macro flexible-link manipulator testbed collaborating with Georgia Institute of Technology. The experiments successfully demonstrated the effectiveness of two control approaches in reducing structural vibration.

Based on the results of the experiments, the combined use of two controllers is recommended for a micro/macro manipulator to achieve the fastest response to commands while canceling disturbances from unexpected forces. 


\section{Contents}

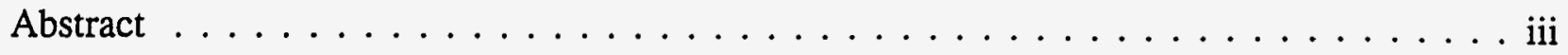

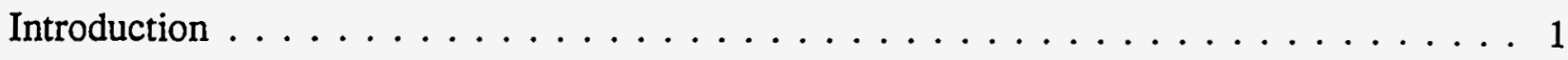

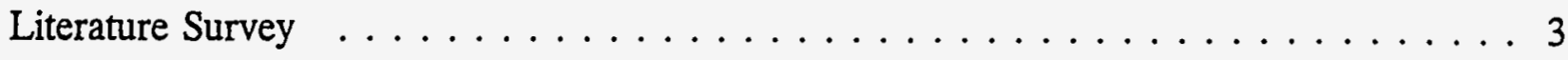

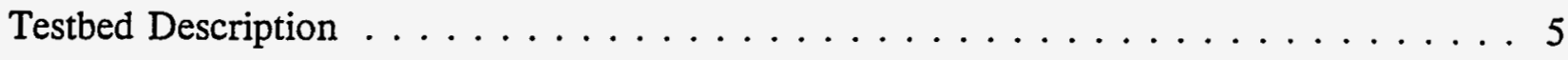

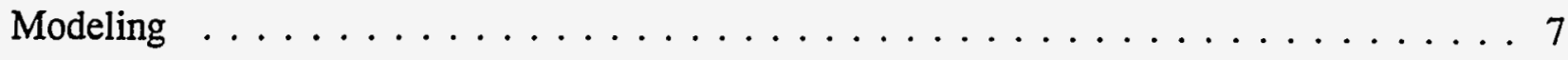

Modified Input Shaping Filter Design $\ldots \ldots \ldots \ldots \ldots \ldots$

Inertial Force Active Damping Controller Design $\ldots \ldots \ldots \ldots \ldots$

Experimental Results and Discussion . . . . . . . . . . . . . . 15

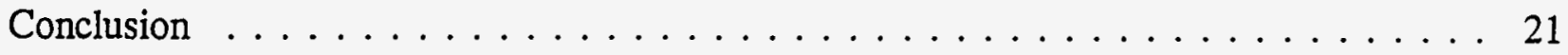

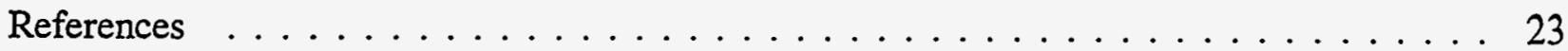




\section{Figures}

1 Micro-/Macro Flexible-Link Manipulator Testbed at Pacific Northwest Laboratory . 5

2 Simplified Model of a Macro/Micro System $\ldots \ldots \ldots \ldots \ldots \ldots$

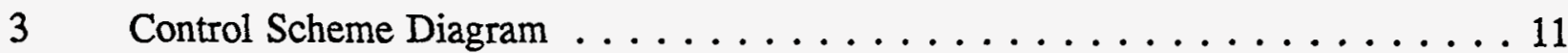

4 Feedforward and Feedback Control Implementation Diagram $\ldots \ldots \ldots \ldots$

5 Step Response of Schilling Titan II Shoulder Joint Angle . . . . . . . . . . . . 16

6 Step Response of Flexible Link Vertical Strain Measurement $\ldots \ldots \ldots$. . . . 16

$7 \quad$ Step Response of Schilling Titan II Azimuth Joint Angle . . . . . . . . . . 17

8 Step Response of Flexible Link Horizontal Strain Measurement . . . . . . . . . 17

$9 \quad$ Schilling Titan II Shoulder Joint Actuator Input $\ldots \ldots \ldots \ldots$

10 Schilling Titan II Azimuth Joint Actuator Input . . . . . . . . . . . . . . 19 


\section{Introduction}

A major goal in many teleoperated robotic applications is to provide both a large manipulator workspace and high accuracy. The concept of a micro-manipulator mounted on the end of a long-reach manipulator may help achieve that goal. The macro-manipulator positions the micro-manipulator to the place of interest within a large workspace. The micro arm then performs fine motions. However, the flexibility of the macro-manipulator structure can be a major obstacle to controlling the micro/macro-manipulator within the desired performance range.

Since 1982, many researchers have worked on flexible-link manipulator control strategies. However, no clear solution has been found for the multiple-link case. Much of the previous research work in flexure control has focused on compensating for vibrations in a macro-manipulator by modulating its own actuators. It is often found, however, that the bandwidth of macro-manipulator actuators limits the effectiveness of this approach. If the bandwidth of macro-manipulator actuators is high enough, using these actuators to damp out vibrations may be dangerous because of the large amount of energy required.

Under the funding and direction of the DOE Office of Technology Development and the Robotics Technology Development Program, researchers at Pacific Northwest Laboratory $(\mathrm{PNL})^{(\mathrm{a})}$ investigated using the inertial force of the micro-manipulator to improve overall micro/macro-manipulator performance. In most cases, the micro-manipulator actuators have the required bandwidth to achieve this goal. Two attractive options for minimizing system structural vibration were implemented and tested: 1) shaping (filtering) the reference inputs and 2) generating inertial forces with the micro-manipulator in response to measured deflection, to actively damp out macro-manipulator vibration.

This report documents the study. The literature surveyed as part of this task is summarized first. Next, the PNL testbed in which the experiments were conducted is described. Then the simplified model providing the conceptual baseline for the control strategy is discussed. The designs for the modified input shaping filter (developed by Georgia Institute of Technology) and the PNL-developed inertial force active damping controller are explained and illustrated. A discussion of the experimental results appears next, followed by the conclusions reached at the end of the study. References cited in this report are listed in the final section.

(a) PNL is a multiprogram national laboratory operated for the U.S. Department of Energy under Contract DE-AC06-76RLO 1830 by Battelle Memorial Institute. 



\section{Literature Survey}

Singer and Seering (1990) developed an input shaping method based on delayed inputs that could be used to exactly cancel the vibratory motion of linear flexible systems, given knowledge of only the natural frequency and damping ratio of each mode. They showed how robustness could be achieved by including additional filter terms. Singh and Vadali (1993) showed that robustness corresponded to multiple zeros placed to cancel the vibratory poles. Singhose et al. (1994) generalized Singer and Seering's original (1990) result, and Magee and Book (in press) showed how to place multiple zeros at the desired location with an arbitrarily small delay. The small delay is desirable to complete the response as quickly as possible and to ensure stability when the filter is placed inside a feedback loop. However, the shortened delay results in magnitudes of the frequency response greater than one for some high frequencies, compromising this advantage. The compromise is a combination of concerns for stability and for increased excitation of the higher flexible modes.

Several researchers have demonstrated the effectiveness of inertial damping. Lee and Book (1990) implemented.a robust control on the Georgia Tech testbed. Lew et al. (1995) illustrated a dramatically effective, yet simple implementation on the PNL testbed based on strain measurements at the base of the flexible link. Lew's implementation is most effective when the small arm is in a configuration that strongly couples the forces generated by the small arm to the appropriate modes of vibration on the large arm. Sharf (1995) simulated a damping algorithm that could generate appropriate inertial forces. However, Sharf's approach did not integrate the damping function with the task functioning of the small arm. No experimental results were presented with the more computationally complex Sharf algorithm. 
$\ldots \ldots$

. 


\section{Testbed Description}

The proposed controllers were studied experimentally on the flexible-link manipulator testbed illustrated in Figure 1. The testbed consists of a Spar 2500 macro-manipulator that has been modified by attaching a 3.4-m-long aluminum alloy flexible link on the tool plate to make the reach $12 \mathrm{~m}$. At the tip of the link, a Schilling Titan II manipulator is installed as a micro-manipulator.

The testbed reach and fundamental natural frequency are similar to those of the macro/micro-manipulator systems expected to be used in large underground nuclear waste storage tanks (Kwon et al. 1993).

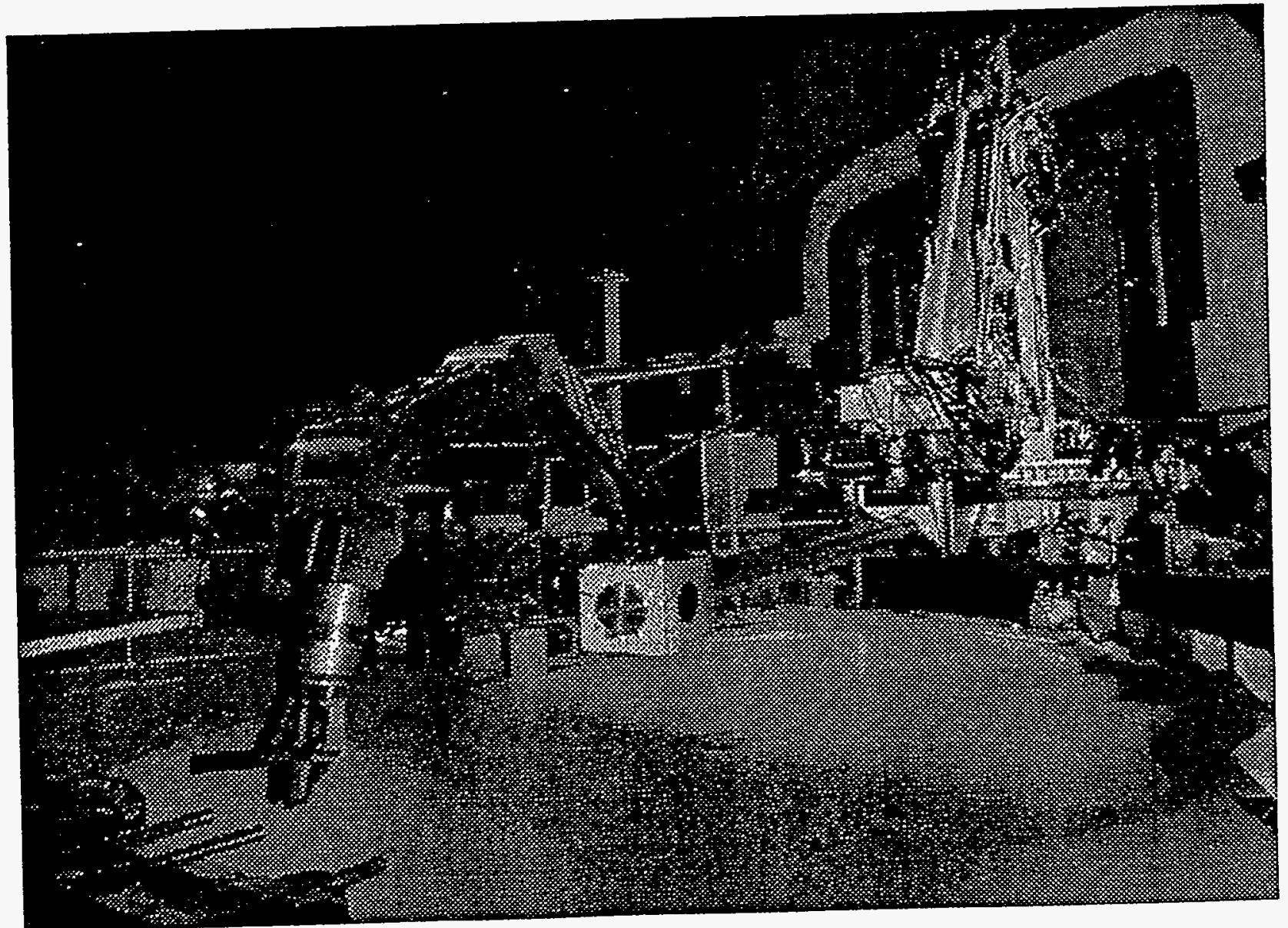

Figure 1. Micro/Macro Flexible-Link Manipulator Testbed at Pacific Northwest Laboratory 
The testbed was successfully teleoperated at the 1995 DOE Robotics Forum held in Albuquerque, New Mexico. A remote input station in Albuquerque was connected via the Internet to the testbed in Richland, Washington, more than $2500 \mathrm{~km}$ away. The operator sent motion commands from the Albuquerque station. Researchers used real-time video of the testbed in motion and displays of system responses such as joint angles, strain measurement, and actuator inputs to demonstrate the effectiveness and reliability of the proposed control scheme.

During the experiments reported here, the testbed was oscillated in the vertical and horizontal planes by the motion of either the Spar or Schilling manipulator. Both the MIS and the IFAD controllers were added to the existing proportional and derivative-independent joint controller for the Schilling manipulator. The MIS acts as a feedforward controller, and IFAD acts as a feedback controller. Strain gage measurements of the flexible link were used as feedback signals to determine the extent of structural vibration control in multiple (vertical and horizontal) directions. 


\section{Modeling}

Deriving the dynamics of multiple flexible-link manipulators can be complex. Lagrangian formulation with the assumed modes method has been widely used (Book 1984). In addition, an efficient method is available for deriving the equation of motion for serially coupled micro/macro systems (Lew and Book 1992).

In this work, however, one flexible link and one rigid link were used to understand the general characteristics of the micro/macro system. This simplified model, shown in Figure 2, gives a conceptual baseline for the control strategy.

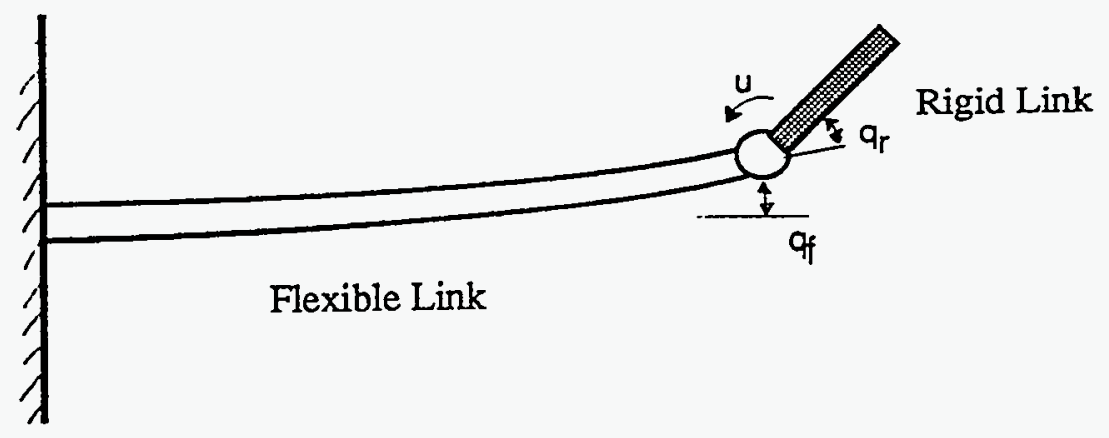

Figure 2. Simplified Model of a Macro/Micro System

The equation of motion of the simplified model can be obtained as

$$
\left[\begin{array}{cc}
M_{r r} & M_{r f} \\
M_{f r} & M_{f f}
\end{array}\right]\left(\begin{array}{l}
\ddot{q}_{r} \\
\ddot{q}_{f}
\end{array}\right)+\left[\begin{array}{cc}
0 & N_{r f} \\
N_{f r} & 0
\end{array}\right]\left(\begin{array}{l}
\dot{q}_{r} \\
\dot{q}_{f}
\end{array}\right)+\left[\begin{array}{ll}
0 & 0 \\
0 & K_{f f}
\end{array}\right]\left(\begin{array}{l}
q_{r} \\
q_{f}
\end{array}\right)=\left[\begin{array}{l}
I \\
b
\end{array}\right]
$$


where

$$
\begin{aligned}
& M_{r r}=I_{r} \\
& M_{r f}=M_{f r}=\psi\left(l_{f}\right) m_{r} l_{r} \cos \left(q_{r}\right) / 2 \\
& M_{f f}=m_{f} \psi^{2}\left(l_{f}\right)+\int_{0}^{l_{f}} \psi^{2}(x) \rho A d x \\
& N_{r f}=N_{f r}=-\psi\left(l_{f}\right) m_{r} l_{r} \sin \left(q_{r}\right) \dot{q}_{r} / 2 \\
& K_{f f}=\int_{0}^{l_{f}} E_{f} J_{f}\left(\frac{\partial^{2} \psi(x)}{\partial x^{2}}\right)^{2} d x \\
& b=\left.\frac{\partial \psi(x)}{\partial x}\right|_{x=l_{f}}
\end{aligned}
$$

$I_{r}$ is the inertia of the rigid link about the rotational axis; $m_{i}$ is the mass of the rigid link or flexible link; $l_{i}$ is the length of the rigid or flexible link; $\psi(x)$ is the mode shape function (only one mode considered); $\mathrm{q}_{\mathrm{r}}$ is the joint angle of the rigid link; $\mathrm{q}_{\mathrm{f}}$ is the flexible-mode, time-dependent coordinate; $E$ is the Young's modulus of the flexible link; $J$ is the crosssectional inertia about the neutral axis of the flexible link; $\rho$ is the density of the link material; and $\mathrm{A}$ is the cross-sectional area of the link.

The gravity term is ignored in this formulation. Assuming a small motion, the system dynamics are linearized about an operating point. The transfer function can then be computed as

$$
\begin{aligned}
G_{r}(s)= & \frac{\overline{q_{r}}(s)}{\bar{u}(s)} \\
& =\frac{\left(M_{f f}-b M_{f \vec{f}}\right) s^{2}+K_{f f}}{\left(M_{r} M_{f f}-M_{r f} M_{f f}\right) s^{4}+K_{f f} M_{r} s^{2}} \\
G_{f}(s)= & \frac{\bar{q}(s)}{\bar{u}(s)} \\
& =\frac{\left(b M_{f f}-M_{f r}\right) s^{2}}{\left(M_{r r} M_{f f}-M_{r f} M_{f r}\right) s^{4}+K_{f f} M_{r} s^{2}}
\end{aligned}
$$

$\mathrm{G}_{\mathrm{r}}$ and $\mathrm{G}_{\mathrm{f}}$ describe the mathematical relationship between input torque and output variables. The upper bar denotes the Laplace transformation. 


\section{Modified Input Shaping Filter Design}

Previous work by Singh and Vadali (1993) has shown that the input shaping method prevents residual vibration by placing filter zeros at the pole locations of the flexible system dynamics. If uncertainty exists in the model, then multiple zeros are placed near the pole locations to add robustness to the shaping method.

Using this pole-zero cancellation concept, a general filtering approach can be developed to cancel a pole $s=\sigma_{1}+j \varpi_{1}$ with a real component $\sigma_{1}$ in the range $\sigma_{1}<0$ and a real component $\varpi_{1}$ in the range $\varpi_{1}>0$. Consider a general two-term, discrete-time filter of the form

$$
F_{2}(z)=\frac{1-z_{1} z^{-1}}{1-z_{1}}
$$

which contains a zero at $z=z_{1}$ and a pole at $z=0$. With a denominator of $\left(1-z_{1}\right)$, the direct current (DC) gain value of the filter is automatically set to 1 .

This discrete-time filter form can be transformed to the continuous s-domain with a substitution of $z=e^{s T}$ into Equation (1). The resulting two-term, continuous filter form is

$$
F_{2}(s)=\frac{1-e^{s_{1} T} e^{-s T}}{1-e^{s_{1} T}}
$$

with zeros in the complex s-plane at

$$
s=\sigma_{1}+f\left(\frac{\varpi_{1} T+2 n \pi}{T}\right)
$$

where $n=0, \pm 1, \pm 2, \ldots, \pm \infty$. It is readily apparent that this filter form places a zero at the pole locations $s=s_{1}$ and that the cancellation is independent of the time delay $T$.

For real physical systems, the model describing the flexible behavior contains real valued coefficients so that any complex pole will always have a complex conjugate partner. This result, from complex variable theory, implies that the filter in Equation (2) must be used to cancel the complex conjugate pair of poles at 


$$
s=\sigma_{1} \pm j \varpi_{1}
$$

The filter that cancels a pair of complex conjugate poles can be written as

$$
F(s)=\frac{\left(1-e^{s_{1} T} e^{-s T}\right)\left(1-e^{s_{1} T} e^{-s T}\right)}{\left(1-e^{s_{1} T}\right)\left(1-e^{s_{1} T}\right)}
$$

where * denotes the complex conjugate. This form of the filter is physically unrealizable because the coefficients are complex. However, it can be simplified to a general three-term filter of the form

$$
F_{3}(s)=\frac{1-2 \cos \left(\omega_{1} T\right) e^{\sigma_{1} T} e^{-s T}+e^{2 \sigma_{1} T} e^{-2 s T}}{1-2 \cos \left(\omega_{1} T\right) e^{\sigma_{1} T}+e^{2 \sigma_{1} T}}
$$

where the subscript 3 denotes the number of terms in the filter.

A similar filter form was derived in the z-domain by Ratten and Feilieu using Wiener filter theory for the feedforward control the flexible arm (Ratten and Feliu 1992).

One can show that the zeros of this general filter form are

$$
s=\sigma_{1}+f\left(\frac{\omega_{1} T+2 n \pi}{T}\right)
$$

where $n=0, \pm 1, \pm 2, \ldots, \pm \infty$. With the general filter in Equation (6), multiple zeros can be placed at pole locations by convolving several of the filters together. However, each filter does not require the same delay time so many possible filter forms exist. 


\section{Inertial Force Active Damping Controller Design}

Based on the conceptual simplified model, the inertial force active damping (IFAD) controller was designed for the testbed as shown in Figure 3. Sequential loop-closure (Maciejowski 1989) was used to design a proportional and derivative (PD) controller and a flexible-motion compensator. With this technique, the PD controller was designed and applied to the system first. Then the flexible-motion compensator was designed for the system with the PD control loop closed. This control architecture can use the existing control system and implements an additional feedback loop to make the necessary adjustment to the actuator signal.

First, the PD feedback controller was designed for the Titan II manipulator (micro arm) fixed to the ground using classical tuning methods (Kuo 1982). The controller gains closely matched those provided by the Titan II manufacturer (Schilling, Inc.). The PD controller provides the desired joint-angle motion with relatively good disturbance rejection. Second, the Titan II manipulator is attached to the macro arm (flexible link and Spar). When a step input is applied to the Titan II as a desired trajectory, the motion of Titan II excites the macro arm's first vibrational mode. The active damping controller is needed to damp out the vibration for such case.

The objective of the flexible-motion compensator (damping controller) is to improve the macro-manipulator settling time. Adding the damping controller to the output of the PD prevents the damping control loop from introducing any steady-state error into the joint angle. Ideally, both the flexible mode $\left(q_{f}\right)$ and its rate would be used for feedback in the damping controller. Realistically, measuring the flexible rate is difficult; therefore, dynamic compensation was used in the damping controller.

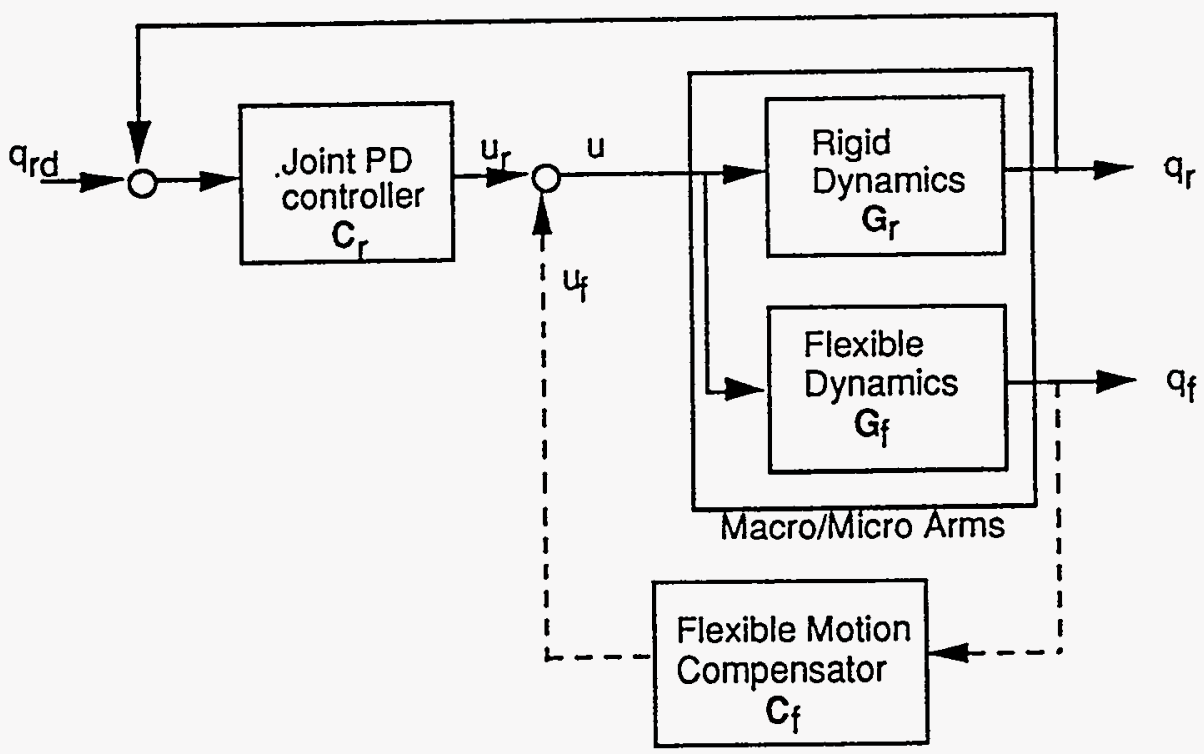

Figure 3. Control Scheme Diagram 
The system model described previously is highly simplified; it is not sufficient for controller design. To obtain more accurate design information, laboratory system identification experiments were conducted. The models identified models were used to construct a damping controller. Several step and frequency response signals were applied to the system under different configurations, and a set of system models was identified using Prony analysis (Pierre et al. 1992) and frequency domain techniques (Trudnowski 1992).

Classical techniques (e.g., root locus methods) were used to design the damping controller that performs well for the set of linear models. The objective was to compensate the flexible mode, $q_{f}$, to provide damping to the first mode while limiting the bandwidth so as not to excite the higher mode. The resulting controller has the form

$$
C_{f}(s)=\frac{T_{1} s}{1+T_{1} s} \frac{k}{1+T_{2} s} \ldots
$$

where $T_{1}$ is a high-pass time constant to remove steady-state offset from the strain signal, $T_{2}$ is a low-pass time-constant to decrease the high-frequency gain, and the remaining terms are lead-lag blocks to provide proper phase compensation.

The flexible-motion compensator was carefully designed such that it adds damping and does not cause instability for the joint-angle motion. After the flexible compensator is added, the system has the same closed-loop characteristics equation for both the rigid-motion and flexible mode; i.e.,

$$
1+C_{r}(s) G_{r}(s)-C_{f}(s) G_{f}(s)=0
$$

So long as the flexible-motion compensator is designed to be stable, the joint-angle motion remains stable.

A major advantage of the controller is that the flexible-motion compensator has an independent loop from the rigid-motion controller. This architecture makes implementation of the active damping controller simpler. When structural vibration becomes a factor to a micro/macro-manipulator performance, the flexible-motion compensator can be added later to the existing rigid-motion controller.

Implementation of the feedforward (MIS) and feedback (IFAD) controllers is diagrammed in Figure 4. 


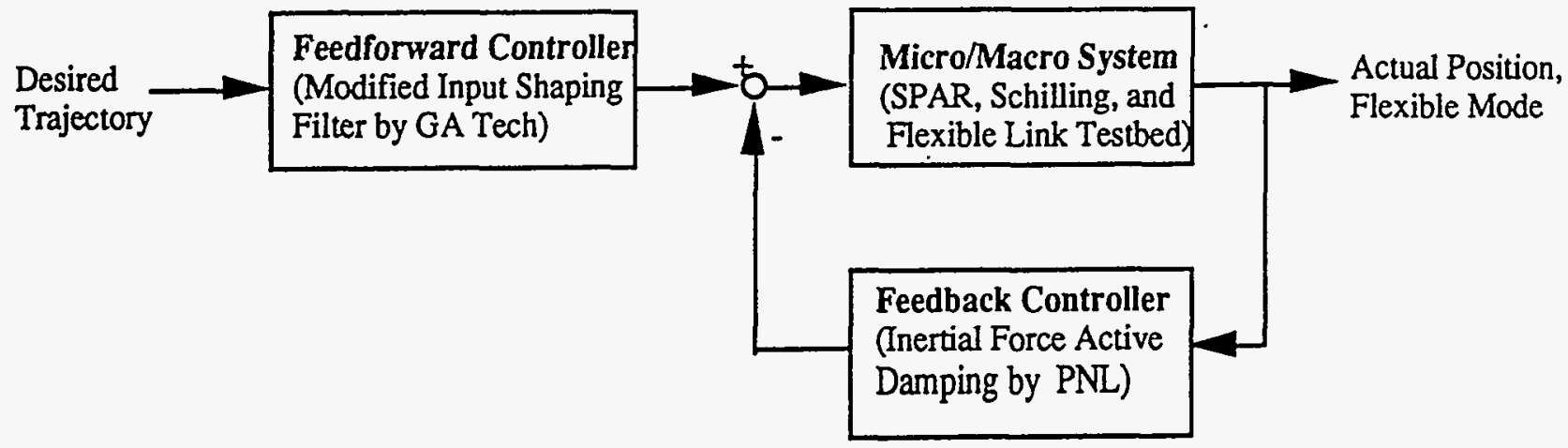

Figure 4. Feedforward and Feedback Control Implementation Diagram 



\section{Experimental Results and Discussion}

The system's natural frequencies were measured in the vertical and horizontal planes by applying an impulse force at the tip of the Titan II manipulator and measuring accelerometer signals in both directions at the base of the manipulator. The lowest natural frequency observed was at $2.14 \mathrm{~Hz}$ in the vertical plane with a damping ratio 0.006 . The second mode was observed at approximately $10.5 \mathrm{~Hz}$, but it is very small and insignificant. The strain gage was installed at the base of the link to efficiently measure the first mode behavior.

Starting with the Titan II manipulator stretched out all the way with the shoulder joint positioned 0 degrees up from horizontal, the shoulder was raised 30 degrees from horizontal with rigid-motion feedback only. Four types of controller responses were collected:

- $\quad$ proportional and derivative (PD)

- $\quad$ PD plus MIS (the feedforward controller)

- $\quad$ PD plus IFAD (the feedback controller)

- $\quad$ PD plus MIS and IFAD (the feedforward and feedback controller together).

Figure 5 shows the shoulder joint-angle response; Figure 6 displays the vertical strain signal response at the base of the flexible link. As the data indicates, although the jointangle reaches the desired angle in 1 second without overshoot, the rigid motion of the Titan II manipulator causes significant vibration in the macro-manipulator (SPAR and flexible link). The vibration lasts more than 40 seconds, with a maximum amplitude of $2.5 \mathrm{~cm}$. This structural vibration causes small oscillations in the joint-angle, as shown in Figure 5.

For horizontal oscillation testing, the Titan II was fully extended with the azimuth joint positioned at 0 degree from the vertical plane and then moved to 30 degrees. Figure 7 is the step response of the Titan II azimuth joint angle; Figure 8 shows the step response of flexible-link horizontal strain measurement.

The MIS filter was implemented to every joint with a time delay 0.058 second, which is one-eighth of the damped natural frequency. As was shown in Figure 4, the MIS is not inside the closed loop. Therefore, there is no stability issue as a feedforward controller. The MIS simply tries to cancel out pole dynamics of the flexible mode; by doing so, it significantly improves that mode's transient response, as indicated in Figures 6 and 8. However, it does not add damping in system response. Therefore, the MIS itself cannot completely eliminate residual vibration.

The IFAD was implemented at azimuth and shoulder joints only. The azimuth joint motion is used to compensate for horizontal vibration; the shoulder joint motion is used for vertical vibration. With the flexible-motion compensator on, the system response improves significantly; the structural vibration is damped out within 2 seconds. The dashed line in 


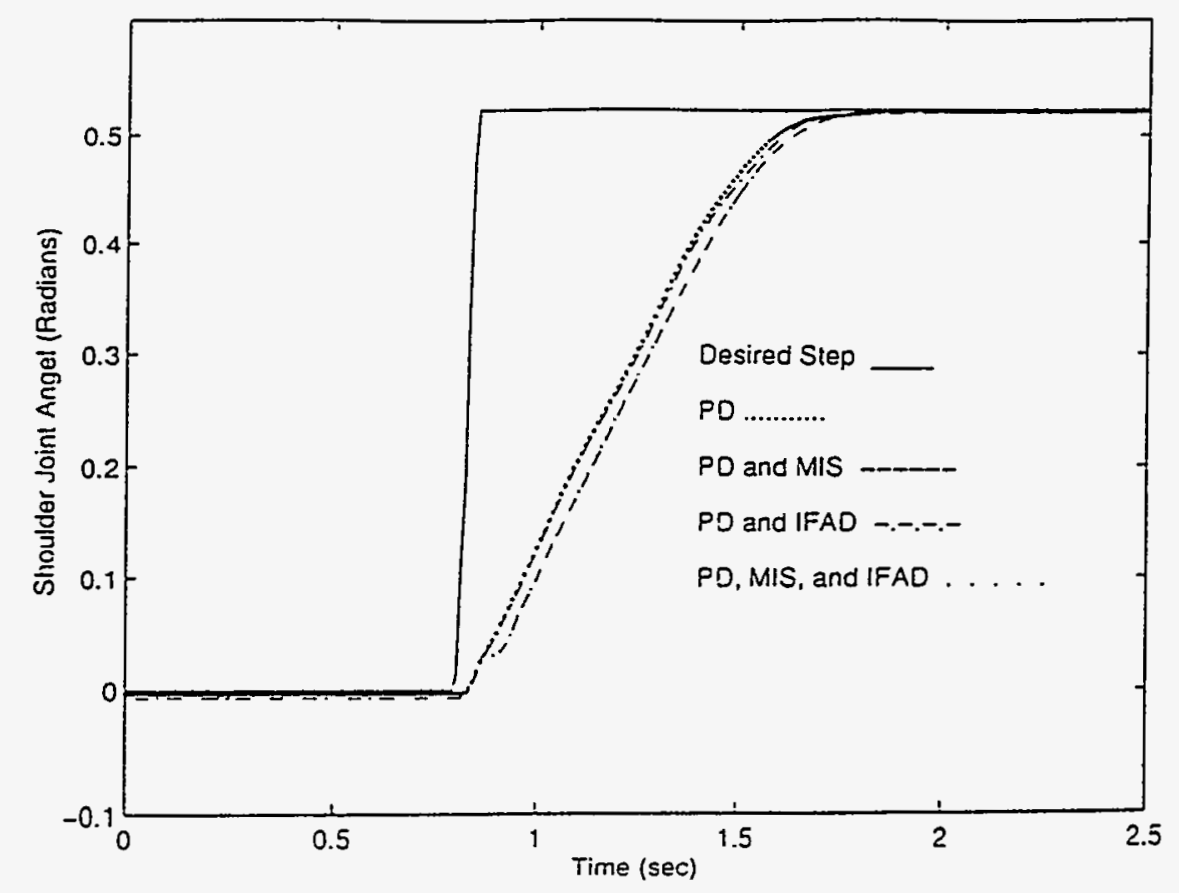

Figure 5. Step Response of Schilling Titan II Shoulder Joint Angle

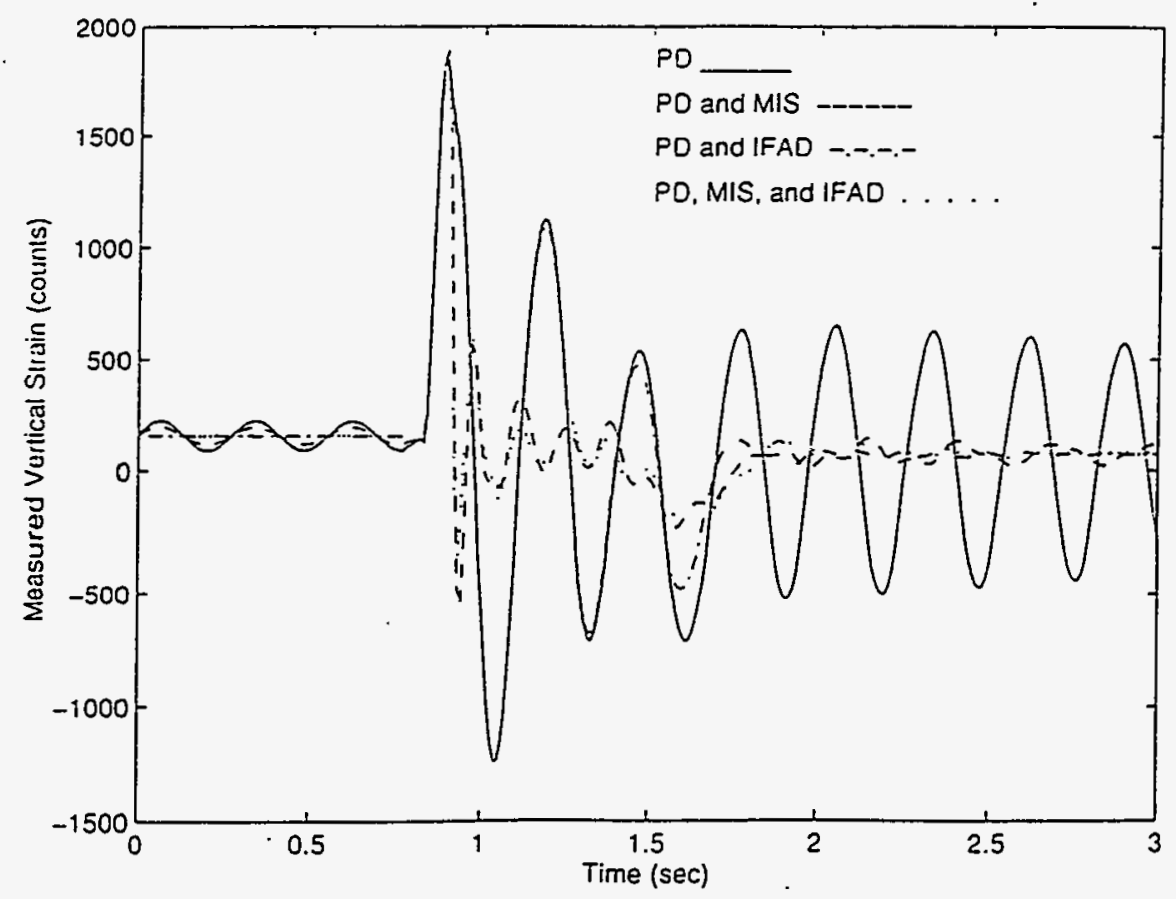

Figure 6. Step Response of Flexible Link Vertical Strain Measurement 


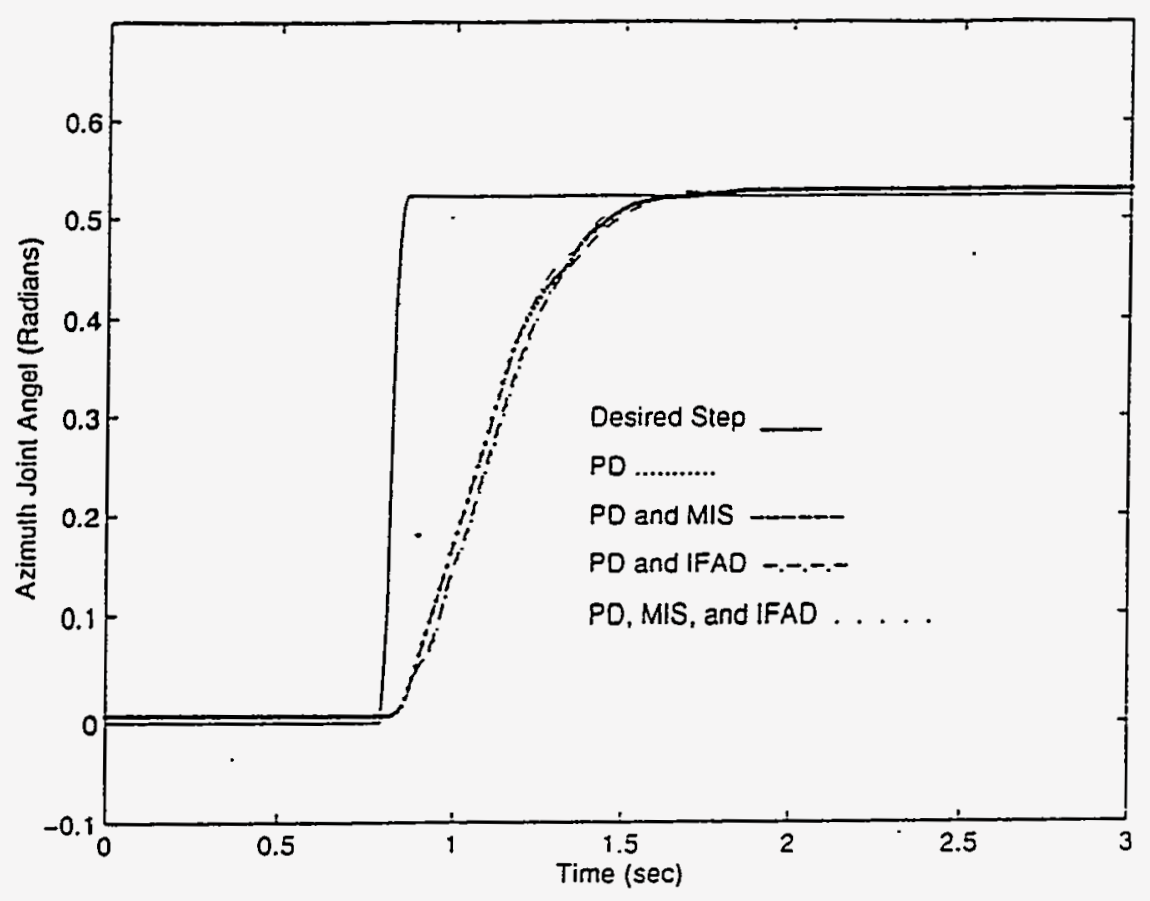

Figure 7. Step Response of Schilling Titan II Azimuth Joint Angle

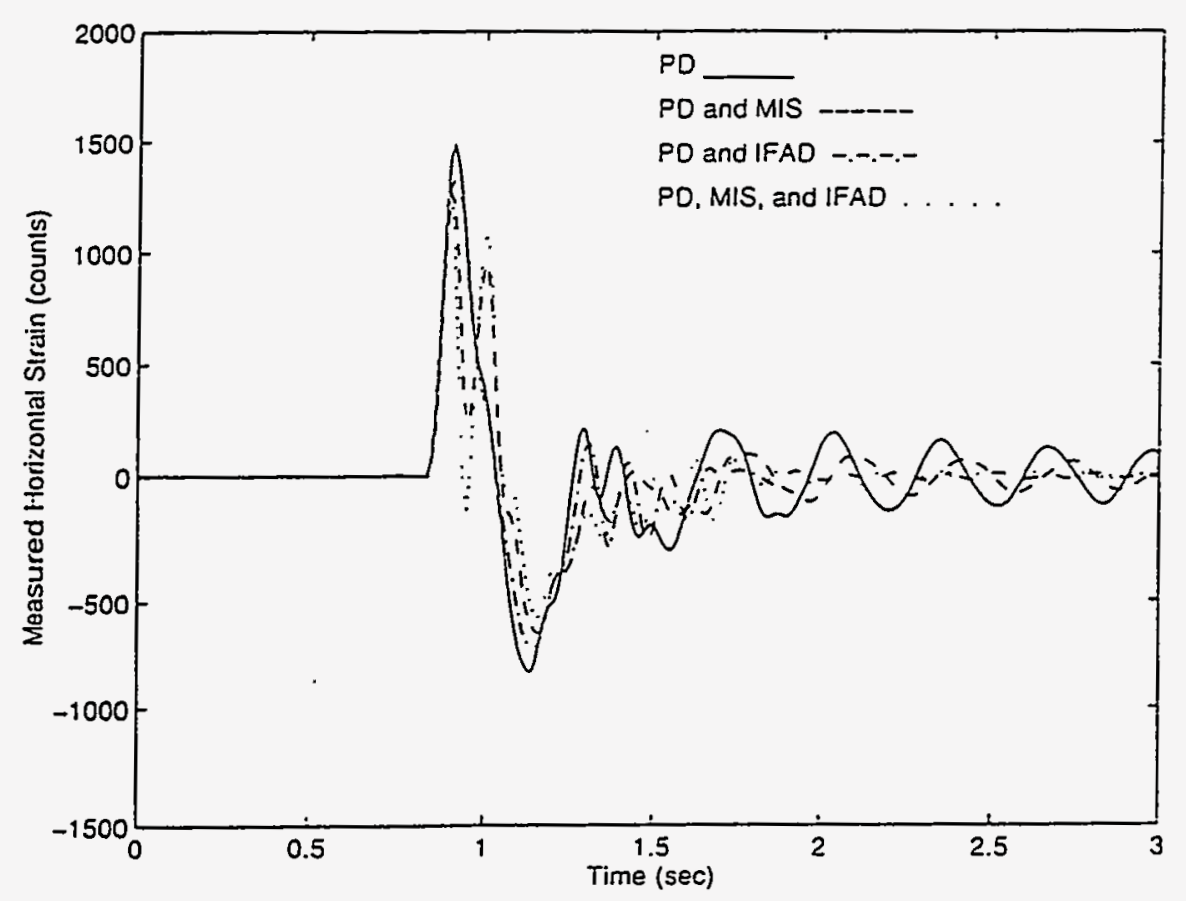

Figure 8. Step Response of Flexible Link Horizontal Strain Measurement 
Figures 6 and 8 indicate the improved performance. This improvement in settling time is significant over the rigid motion controller only in the settling time. The shoulder-joint angle displays a slightly larger overshoot, but settles faster. The overshoot action of the micro arm is the generating inertial force to damp out the structural vibrations. However, the transient response is worse than the MIS case.

To obtain best performance, the MIS and IFAD should be combined. The MIS feedforward controller improve the transient reponse, and the IFAD feedback controller provides faster settling time. Figure 6 and 8 demonstrate its results again as we expected.

Figures 9 and 10 show the actuator input signal required to control the Schilling Titan II joints in both cases. The IFAD requires little control effort; that is, it deviates little from PD controller output. A slight change of the actuator input achieves significant damping in the response. On the other hand, the MIS requires large torque because it must work fast to improve transient response in a short time.

Demonstration video tapes of the above experiments are available. 


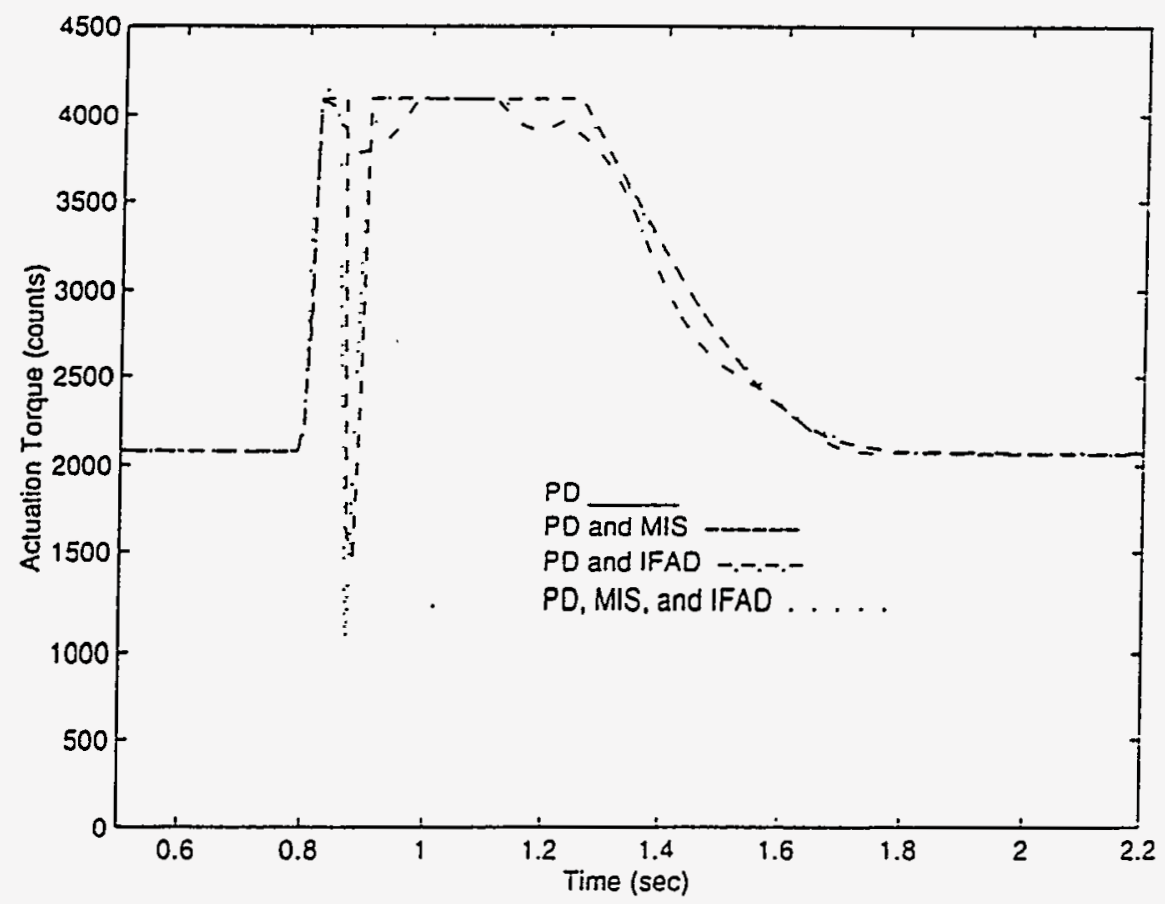

Figure 9. Schilling Titan II Shoulder Joint Actuator Input

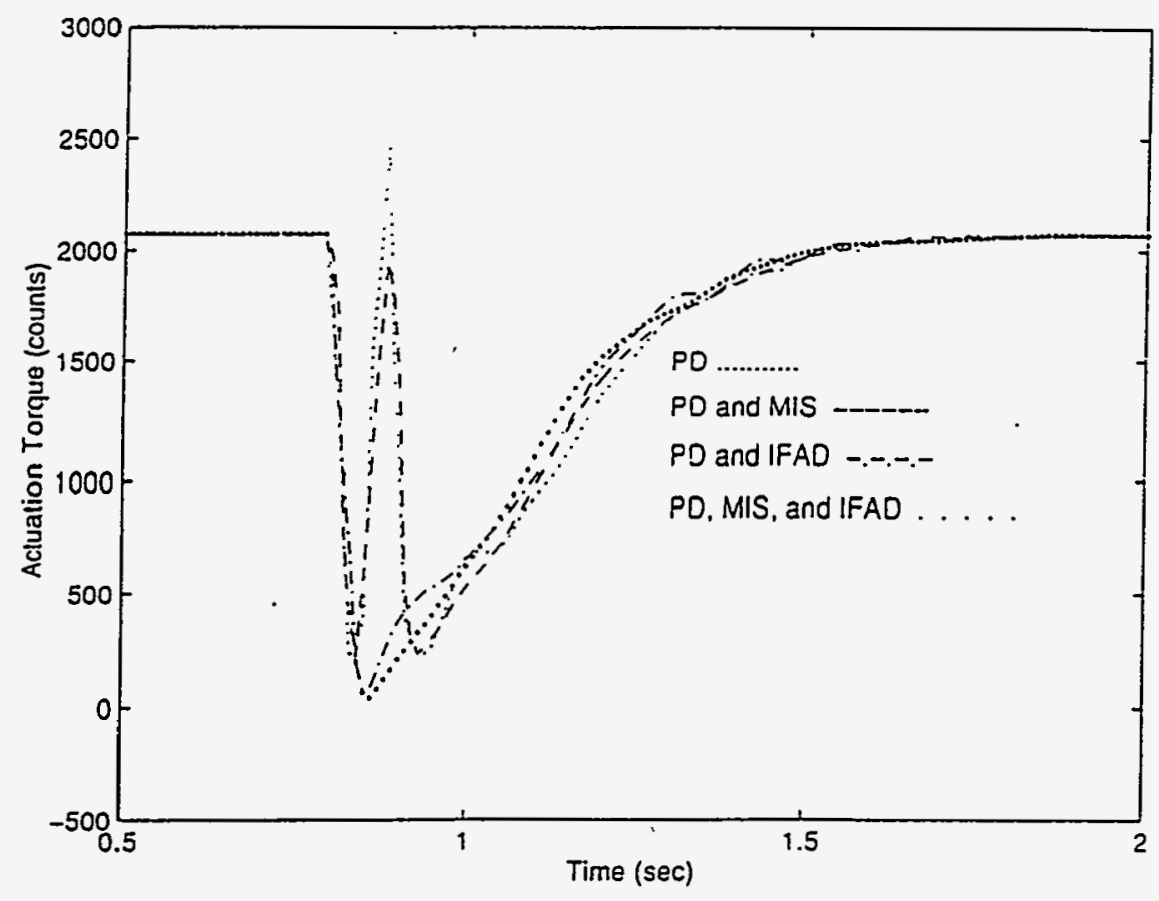

Figure 10. Schilling Titan II Azimuth Joint Actuator Input 


\section{Conclusion}

This experimental study, conducted using a testbed of industrial robotic arms, demonstrated the effectiveness of the modified input shaping and the inertial force damping control in micro/macro-manipulator. The micro-manipulator not only moved to a desired position, but also counteracted the structural vibration of the macro-manipulator. Multiplane oscillations were damped very well. The time-response results indicated that this controller combination improved settling time by $2000 \%$. The combination also improved transient response magnitude by a factor of 2 .

The effectiveness of inertial force control was successfully demonstrated in the micro/macro-manipulator system described in this report. However, this does not guarantee that it will work for every micro/macro-manipulator. For example, the inertia of a micromanipulator may not generate a force large enough to damp out or cancel out the structural vibration of the system if the micro arm is too small or is positioned at certain

configurations. One way to examine the feasibility of inertial force damping is to study the controllability of the system with the joint angle of the micro-manipulator as the input and the structural mode as the output. 


\section{References}

Book, W. J. 1984. "Recursive Lagrangian Dynamics of Flexible Manipulator Arm." International Journal of Robotics Research 3(3):62-75.

Kuo, B. C. 1982. Automatic Control Systems. Prentice-Hall, Englewood Cliffs, New Jersey.

Kwon, D., S. March-Leuba, S. Babcock, B. Burks, and W. Hamel. 1993. "Parametric Design Studies of Long Reach Manipulators." In Proceedings of ANS Fifth Topical Meeting on Robotics and Remote Systems, pp. 265-273. April 25-30, 1993, American Nuclear Society, Knoxville, Tennessee.

Lee, S.-H., and W. J. Book. "Robot Vibration Control Using Inertial Damping Forces." In Proceedings of VIII CISM-IFToMM Symposium on the Theory and Practice of Robots and Manipulators (Ro.Man.Sy. '90), July 2-6, 1990, Cracow, Poland.

Lew, J. Y., and W. J. Book. 1992. "Dynamics of Two Serially Connected Flexible Arms." In Advanced Control Issues for Robot Manipulators: ASME92 Winter Annual Meeting, DSCVol. 39, pp. 17-22. November 1992, American Society for Mechanical Engineers, Anaheim, California.

Lew, J.Y., D. J. Trudnowski, M. S. Evans, and D. W. Bennett. 1995. "MicroManipulator Motion Control to Suppress Macro-Manipulator Structural Vibrations." In Proceedings of the 1995 IEEE International Conference on Robotics and Automation. May 24-26, 1995, Nagoya, Japan. In press.

Maciejowski, J. M. 1989. Multivariable Feedback Design. Addison-Wesley Publishing, New York.

Magee, D. P., and W. J. Book. 1995. "Filtering Micro-Manipulator Wrist Commands to Prevent Flexible Base Motion." In Proceedings of the 1995 American Control Conference, pp 2538-2542. June 21-23, 1995, Seattle, Washington.

Pierre, D., D. J. Trudnowski, and J. F. Hauer. 1992. "Identifying Linear Reduced-Order Models for Systems with Arbitarary Initial Conditions Using Prony Signal Analysis." IEEE Trans. on Automatic Control 37(6):831-835.

Ratten, K. S., and V. Feliu. 1992. "Feedforward Control of Flexible Manipulators." In Proceedings of the 1992 IEEE International Conference on Robotics and Automation, Vol.1, pp. 788-793. May 12-14, 1992, Nice, France. Institute of Electrical and Electronics Engineers, Piscataway, New Jersey. 
Sharf, I. 1995. "Active Damping of a Large Flexible Manipulator with a Short Reach Robot." In Proceedings of the 1995 American Control Conference, pp 3329-3333. June 2123, 1995, Seattle, Washington.

Singer, N. C., and W. P. Seering. 1990. "Preshaping Command Inputs to Reduce System Vibration." ASME Journal of Dynamic Systems, Measurement, and Control 115(1):76-82.

Singh, T., and S. R. Vadali. 1993. "Robust Time-Delay Control." ASME Journal of Dynamic Systems, Measurement, and Control 115(2A):303-306.

Singhose, W. E., N. C. Singer, and W. P. Seering. 1994. "Design and Implementation of Time-Optimal Negative Input Shapers." In Dynamic Systems and Control - Proceedings of the 1994 ASME Winter Annual Meeting, DSC-Vol. 55-1, pp. 151-157. November 6-11, 1994, Chicago, Illinois.

Trudnowski, D. J. 1992. Frequency Domain Transfer Function Identification Using the Computer Program SYSFIT. PNL-8455, Pacific Northwest Laboratory, Richland, Washington. 


\section{Distribution}

No. of

Copies

Offsite

2 DOE/Office of Scientific and Technical Information

W. J. Book

School of Mechanical Engineering

Georgia Institute of Technology

Atlanta, GA 30332-0405

B. L. Burks

Lockheed Martin Energy Systems

Oak Ridge National Laboratory

Building 7601, Mail Stop 6304

P.O. Box 2008

Oak Ridge, TN 37831-6304

D. Horschel

Sandia National Laboratory

Dept. 2161, MSO 952

1515 Eubank SE

Albuquerque, NM 87123

R. Kress

Lockheed Martin Energy Systems

Oak Ridge National Laboratory

Building 7601, Mail Stop 6304

P.O. Box 2008

Oak Ridge, TN 37831-6304

S. Slezak

Sandia National Laboratory

Building 962, Mail Stop 1177

1515 Eubank SE

Albuquerque, NM 87123
No. of

Copies

Onsite

DOE Richland Operations Office

D. A. Brown

K8-50

MACTC

V. Fitzpatrick

K8-50

Westinghouse Hanford Company

B. A. Carteret

N1-21

15 Pacific Northwest Laboratory

S. A. Bailey K5-08

W. F. Bonner K9-14

J. Y. Lew (5) K5-22

M. W. Rinker K5-26

B. F. Saffell, Jr. K5-22

J. T. Smalley

K5-22

Technical Report Files (5)

P8-55 